\title{
INTEGRALISME PENGETAHUAN: Pertautan Nilai Islam dan Sains Modern
}

\author{
Oleh: Ikmal
}

\begin{abstract}
Abstrak
Islam merupakan agama yang sempurna dan suatu sistem total, maka nilainilai yang terkandung di dalamnya, harus meliputi setiap aspek kehidupan manusia. Apakah itu struktur politik atau organisasi sosial, kegiatan ekonomi atau kurikulum pendidikan, proses pembelajaran, penyelidikan ilmiah maupun penguasaan teknologi. Disinilah perlunya mengintegrasikan nilai-nilai Islam ke dalam ilmu pengetahuan umum, sehingga lahirlah ilmu pengetahuan utuh yang sarat dengan nilai-nilai religius yang memberikan kemudahan, manfaat dan ketenangan bagi manusia dan lingkungan sekitarnya.
\end{abstract}

Kata Kunci : Integralisme, nilai-nilai Islam, Humanisme, Sains Modern dan Pencerahan.

\section{Pendahuluan}

Menjelang berakhirnya abad ke-20, kita dapat menyaksikan puncak-puncak kemajuan ilmu dan teknologi. Apa yang dianggap mustahil, bahkan tidak terbayangkan, kini menjadi kenyataan-kenyataan yang menakjubkan berkat perkembangan ilmu dan teknologi modern. Namun di balik kemajuan-kemajuan ilmu pengetahuan dan teknologi di berbagai bidang tersebut, muncul gejala-gejala merosotnya kepercayaan orang terhadap ilmu pengetahuan dan teknologi.

Menurut Azumardi bahwa manusia modern meyakini bahwa Ilmu pengetahuan dan teknologi merupakan satu-satunya jalan yang mampu mengantar kepada kemajuan dalam kehidupan. Tetapi keyakinan ini mulai berubah ketika manusia menyaksikan bahwa ilmu pengetahuan dan teknologi tidak hanya mendatangkan kemajuan dan kenyamanan, tetapi juga berbagai problem kemanusiaan dan demoralisasi kultural dan spiritual 
cukup parah, yang tidak mudah bisa diatasi. ${ }^{1}$ Sehingga dampak negatif ilmu pengetahuan dan teknologi akan menimbulkan ancaman bagi peradaban manusia.

Dampak negatif ilmu pengetahuan dan teknologi tersebut telah menciptakan manusia-manusia rakus, tanpa hati nurani dan tidak berpikir jauh serta mengeksloitasi kekayaan alam tanpa batas tertentu (bersifat boros) dalam penggunaan energi, misalnya energi migas dipergunakan secara berlebihan, padahal sumber-sumber energi tersebut akan habis. Begitupun keperluan manusia akan energi semakin meningkat yang berakibat menipisnya bahan energi jika dipakai terus menerus.

Maka mulailah manusia mencari alternatif lain dengan menggunakan sumber tenaga yang tidak konvensional seperti sumber tenaga nuklir. Namun eksploitasi sumber tenaga nuklir tersebut, disamping membawa dampak positif bagi manusia, juga membawa dampak negatif dan pengaruh destruktif yang luas sekali dibidang pertahanan dan keamanan, sehingga dapat menimbulkan pemusnahan total bagi umat manusia. $^{2}$

Dengan demikian, kemajuan di bidang ilmu pengetahuan dan teknologi telah menghasilkan banyak manfaat dan kenikmatan hidup. Tetapi bersamaan dengan itu juga ada sisi yang sangat buruk dan gelap karena dapat mendatangkan kekejaman yang mengerikan, seperti penyalahgunaan tenaga nuklir pada perang dunia kedua yang meluluhlantakkan kota Hirosyima dan Nagasaki. Selanjutnya penyalahgunaan senjata kimia-notabenenya terlarang untuk digunakan-yang dilakukan Zionis-Yahudi terhadap umat Islam di GazaPalestina. Sehingga tragedi penggunaan senjata-senjata pemusnah massal

\footnotetext{
${ }^{1}$ Azyumardi Azra, Paradigma Baru Pendidikan Nasional (Cet. I; Jakarta: PT. Kompas Media Nusantara, 2002), h. 189.

${ }^{2}$ R.H.A. Sahirul Alim, Menguak Keterpaduan Ilmu pengetahuan, Teknologi dan Islam (Cet. I; Yogyakarta: Titian Ilahi, 1998), h. 77.
} 
ini, telah memberikan bekas dan trauma berkepanjangan bagi sejarah peperangan umat manusia.

\section{Pembahasan}

Menurut A.M. Saefuddin, manusia modern mengalami kejatuhan dari posisinya sebagai makhluk yang paling mulia dan sebagai khalifah fi al-ard bermula dari tampilnya humanisme di Eropa, yang ditandai dengan adanya renaissance, yakni kerinduan akan nilai-nilai budaya-leluhur Yunani dan Romawi, yang kering nilai-nilai spiritual. Lewat corong renaissance, humanisme mempromosikan supremasi kemanusiaan melebihi batas-batas fitrah manusia itu sendiri. Manusia memahami alam hanya sebatas jangkauan akalnya. Humanisme telah mewarnai cara berpikir manusia modern dan telah sengaja diciptakan untuk menyeret manusia kepada formalitas kehidupan. Padahal humanisme ini, telah lama terperangkap dengan dengan dogma-dogma materialis yang hanya menjadi paradoks bagi manusia dan begitu rumit mencari solusi penyelesaiannya. Di mana manusia sangat mendewakan kekuatan rasionya tanpa memberikan ruang sedikitpun kepada nilai-nilai transenden dalam mempengaruhi perilakunya. ${ }^{3}$ Cara berpikir humanisme ini ternyata membuat kemunduran Barat dari segi spiritual, kemunduran tersebut disebabkan oleh Bacon, Descartes dan Aguste Comte.

Roger Bacon, orang yang dipandang Barat sebagai "Bapak" dari metode eksprimental di dalam ilmu pengetahuan mengakui bahwa kerja ilmiahnya mengambil dari karya terjemah buku optik karangan seorang muslim yakni Ibn Haitham, dengan memisahkan nilai-nilai Islam dengan ilmu eksperimental.

Demikian juga Rene Descartes yang menyatakan dengan tegas bahwa seseorang harus memisahkan masalah-masalah moral dan iman dari

${ }^{3}$ Ahmad M. Saefuddin, et al, Desekularisasi pemikiran: Landasan Islamsasi (Cet. IV; Bandung: Mizan Anggota IKAPI, 1998), h. 46. 
wilayah rasio, tujuan hidup dan masalah-masalah yang transenden tidak perlu di masuki oleh akal. Pola pemikiran ini melahirkan paham positivism Aguste Comte, yakni menolak keberadaan sesuatu yang transenden yang tidak bisa dibuktikan secara empirik dengan indera atau tidak dapat diukur dengan matematika, menjadi kerangka kerja yang menamakan dirinya "ilmu modern" atau "ilmu Barat". ${ }^{4}$ Pola pemikiran demikian telah membuat manusia modern menjadi sombong dengan cara berpikir "positif-nya". Sehingga hanya yang eksperimental sajalah yang dikatakan ilmiah. Perasaan, intuisi, bahkan wahyu dikategorikan sebagai gejala psikologis yang bersifat subjektif saja, dan dianggap tidak ilmiah.

Dari pandangan hidup yang formalitas ini, dapat menimbulkan sikap individualitas dalam kehidupan bermasyarakat. Hal ini menjauhkan manusia dari esensi dan eksistensinya. Sehingga lahirlah dikotomi di berbagai sektor kehidupan, termasuk dikotomi ilmu pengetahuan dan lembaga pendidikan.

Padahal Islam merupakan ajaran yang utuh dan tidak ada pemisahan antara yang sakral dan yang profan, yang sekular dan yang religius. Sedangkan ilmu pengetahuan Barat—yang merupakan acuan ilmu pengetahuan yang membawa kemajuan — secara khusus bersifat sekular dan merusak nilai-nilai dasar Islam serta berlawanan dengan kesadaran historis terdalam dari komunitas umat. ${ }^{5}$

Oleh karena itu, ilmu pengetahuan yang operasional sangat dibutuhkan untuk membangun sebuah peradaban - khususnya peradaban Islam. Ilmu pengetahuan harus sarat dengan nilai-nilai Islam yang abadi. Tanpa hal itu, umat Islam selamanya terus menjadi konsumen dari produk

${ }^{4}$ Maurice Bucaille, The Quran and Science, disunting oleh Khozin Afandi, Pengetahuan Modern dalam al-Qur'an (Cet. I; Surabaya: Al-Ikhlas, 1995), h. 45-46.

${ }^{5}$ Ziauddin Sardar, Jihad Intelektual; Merumuskan Parameter-parameter Ilmu pengetahuan Islam, diterjemahkan oleh AE Priyono (Cet. I; Surabaya: Risalah Gusti, 1998), h. 120 . 
peradaban Barat dan terus mengekor pada setiap kemajuan yang ditampilkan oleh Barat tanpa memperhatikan latar belakang budaya, norma dan nilai yang berbeda. Sehingga mustahil peradaban Islam yang selalu dinanti-nantikan akan muncul kembali kepermukaan sebagaimana pada masa keemasannya.

Islam merupakan agama yang sempurna dan suatu sistem total, maka nilai-nilai yang terkandung di dalamnya, harus meliputi setiap aspek kehidupan manusia. Sehingga tidak satupun lepas dari sentuhan nilai-nilai Islam. Apakah itu struktur politik atau organisasi sosial, kegiatan ekonomi atau kurikulum pendidikan, proses pembelajaran, penyelidikan ilmiah maupun penguasaan teknologi. Nilai-nilai akan memberikan ukuran dan batasan bagi masyarakat muslim, dan sekaligus petunjuk bagi peradaban Islam. Disinilah perlunya mengintegrasikan nilai-nilai Islam ke dalam ilmu pengetahuan umum, sehingga lahirlah ilmu pengetahuan utuh yang sarat dengan nilai-nilai religius yang memberikan kemudahan, manfaat dan ketenangan bagi manusia dan lingkungan sekitarnya.

Kesadaran umat Islam akan ketertinggalannya dibidang ilmu dan teknologi dibanding Barat, membuat umat Islam bangkit dan menyusul ketertinggalannya dengan merombak pola pikir yang selama ini membawa kebekuan dengan melalui kebebasan penalaran intelektual, dan kajiankajian rasional-empirik, filosofis dengan tetap menjurus kepada kandungan al-Qur'an dan hadis, serta menggelar berbagai diskusi untuk mencari format ideal bagi pendidikan Islam.

Pada tahun 1977, konferensi muslim dunia pertama mengenai pendidikan Islam, mengajukan salah satu usaha untuk menghilangkan dikotomi sitem pendidikan yang ada di seluruh dunia muslim. Diputuskan bahwa jalan yang harus ditempuh adalah perlu segera dirumuskan sistem terpadu bidang keilmuan. Semua cabang ilmu harus diintegrasikan dengan 
ajaran-ajaran Islam, karena pendidikan Barat dianggap hanya dapat mengembangkan peradaban materialistik belaka. ${ }^{6}$

Ziauddin Sardar memberikan solusi dalam merumuskan konsep sains Islam yakni, pertama, dari segi epistemologi, umat Islam harus berani mengembangkan kerangka pengetahuan masa kini yang terartikulasi sepenuhnya. Kerangka pengetahuan yang dikembangkan dapat membantu mengatasi masalah-masalah moral dan etika; kedua, perlu ada gaya-gaya dan metode-metode aktivitas ilmiah dan teknologi yang sesuai tinjauan dunia, tetapi islami; ketiga, perlu ada teori sistem pendidikan yang memadukan ciri-ciri terbaik sistem tradisional dan sistem modern (integralistik). ${ }^{7}$

Selanjutnya Isma'il Raji al-Faruqi memberikan solusi bahwa islamisasi ilmu pengetahuan merupakan salah satu langkah untuk menghilangkan dikotomi dalam pendidikan. Langkah yang dimaksud ialah: pertama, semua kajian baik yang berkaitan dengan manusia maupun alam, agama maupun sains, harus menata kembali dirinya berdasarkanprinsipprinsip tauhid; kedua, ilmu-imu yang mengkaji tentang hubungan dengan sesama manusia harus mengenali manusia bahwa manusia berada pada tempat yang secara metafisik dan aksiologik dikuasai Allah swt.; ketiga, ilmu-ilmu humaniora hendaknya tidak diintimidasi oleh ilmu-ilmu fisika, karena keduanya memiliki metode yang sama, yang berbeda hanya objek kajiannya; dan keempat, islmisasi ilmu pengetahuan harus menunjukkan keterkaitan antara relitas yang dikaji dengan aspek ilahiah. ${ }^{8}$

${ }^{6}$ Syed Sajjad Husain dan Syed Ali As\}raf, Crisis Muslim Eduction, terj. Rahmani Astuti, Menyongsong Keruntuhan Pendidikan Islam (Cet. V; Bandung: Gema Risalah Press, 1994), h. 79.

${ }^{7}$ Ziauddin Sardar, The Future of Muslim Civilization, terj. Rahmani Astuti, Rekayasa Masa Depan Peradaban Muslim (Cet. III; Bandung: Mizan, 1991), h. 280-281.

${ }^{8}$ Abubaker A. Bagader, Islamisasi Ilmu Pengetahuan" dalam Islam dan Perspektif Sosisologik (Cet. I; Surabaya: Amarpress, 1991), h. 12-14. 
Selanjutnya, keempat langkah tersebut dijabarkan lebih lanjut menjadi dua belas langkah yang harus ditempuh, yaitu: pertama, penguasaan terhadap disiplin-disiplin modern. Hal ini dimaksudkan bahwa untuk dapat menguasai suatu disiplin, harus dikuasai metodologi, obyek kajiannya, dan sebagainya. Kedua, Survei disipliner, dimaksudkan agar sarjana-sarjana muslim mampu menguasai disiplin ilmu modern. Ketiga, penguasaan terhadap khazanah Islam dengan membuat antologi-antologi warisan pemikiran Islam yang berkaitan dengan disiplin ilmu. Keempat, penguasaan terhadap khazanah Islam untuk tahap analisa dari perspektif masalah-masalah kekinian. Kelima, penentuan relevansi spesifik untuk setiap disiplin ilmu. Keenam, penilaian kritis terhadap disiplin modern dari titik pijak Islam. Ketujuh, penilaian kritis terhadap khazanah Islam untuk kemudian dirumuskan relevansi kontemporernya. Kedelapan, Survei problem yang dihadapi umat Islam dalam dimensi politik, ekonomi, intelektual, kultur, dan sebagainya. Kesembilan, survei masalah-masalah umat manusia. Kesepuluh, analisa kreatif dan sintesa, sarjana-sarjana muslim siap melakukan sintesa dalam rangka menjembatani jurang kejumudan yang berabad-abad. Kesebelas, merumuskan kembali disiplindisiplin di dalam kerangka Islam. Kedua belas, Penyebarluasan ilmu pengetahuan yang sudah diislamisasikan.

Langkah yang diajukan al-Faruqi tersebut tampaknya sangat sederhana, tetapi memiliki pandangan yang komprehensif terhadap proses islamisasi pengetahuan, atau lebih tepat dikatakan sebagai ilmuisasi Islam. Oleh karena itu, dalam rangka islamisasi ilmu pengetahuan itu, pengintegrasian ilmu-ilmu agama dengan ilmu umum mesti dilakukan. Pengintegrasian itu sendiri menurut Abubaker A. Bagader tergantung pada dua prinsip. Pertama, para peneliti muslim harus merancang kajian sosial dari perspektif Islam. Kedua, kajian Islam sebagai displin harus 
dintegrasikan dengan pesoalan-persoalan sosial untuk memecahkan masalah sekularisasi pendidikan. ${ }^{9}$

Dalam konteks ke-Indonesiaan, upaya integralisasi ilmu pengetahuan juga terus diupayakan. Abdurrahman Mas'ud menawarkan humanisme religius sebagai sebuah paradigma dalam rangka menghilangkan dikotomi dalam sistem pendidikan Islam dengan beberapa alasan, yaitu: pertama, keberagamaan yang cenderung menekankan hubungan vertikal dan kesemarakan ritual. Implikasi dari keberagamaan yang sering ditampilkan adalah lebih mengutamakan kesalehan ritual daripada kesalehan sosial. Hal ini pada gilirannya berimplikasi pada relitas social yang dihiasi dengan budaya ritualistik, kaya kultur yang bernuansa agama, tetapi miskin dalam nilai-nilai spiritual yang berpihak pada kemanusiaan. Kedua, kesalehan sosial masih jauh dari orientasi masyarakat. Kesalehan yang merupakan output pendidikan Islam, sering tidak memenuhi kebutuhan masyarakat. Masyarakat membutuhkan output yang saleh dalam spiritual, cerdas dalam intelektual, dan peka dalam sosial (insan $k a>m i l$ ). Ketiga, Potensi peserta didik belum dikembangkan secara proporsional, pendidikan belum berorientasi pada pengembangan sumber daya manusia (undevelopmentresources). Pendidikan di Indonesia masih teacher-oriented, kendatipun paradigma tersebut sudah dirubah melalui perubahan kurikulum seperti Kurikulum Berbasis Kompetensi (KBK), kemudian disempurnakan dengan Kurikulum Tingkat Satuan Pendidikan (KTSP), tetapi belum didukung oleh sarana yang memadai, sehingga penerapan kurikulum tersebut belum maksimal. Keempat, dunia pendidikan di Indonesia belum mampu melahirkan output yang mandiri dan bertanggung jawab. Kemandirian dan tanggung jawab pribadi peserta didik belum dapat dibentuk, boleh jadi

${ }^{9}$ Ibid., h. 28. 
karena alasan geofisik atau adapt ketimuran yang masih mendidik anak dengan memanjakannya. ${ }^{10}$

Di samping itu, Shodiq Abdullah mengajukan solusi mengatasi dikotomi ilmu dalam pendidikan Islam adalah dengan rekonsiliasi epistemologi agar rumusan sistem pendidikan Islam lebih fungsional dan marketable di masa depan. ${ }^{11}$ Jika hal ini tidak dilakukan, maka sistem pendidikan Islam tidak akan mampu menghadapi perubahan dan menjadi counter ideas terhadap globalisasi kebudayaan. ${ }^{12}$ Hal lain yang dilakukan dalam menghilangkan dikotomi terhadap pendidikan Islam adalah dengan mengintegrasikan antara ilmu agama dengan ilmu umum, dengan mengislamkan atau melakukan purifikasi (penyucian) terhadap ilmu pengetahuan produk Barat, sehingga diperoleh ilmu pengetahuan yang islami. $^{13}$

Kuntowidjoyo menawarkan lima langkah untuk menghilangkan dikotomi ilmu pengetahuan, yaitu: pertama, memasukkan mata kuliah keislaman sebagai bagian integral dari sistem kurikulum yang ada. Kedua, menawarkan berbagai mata kuliah dalam studi keislaman. Ketiga, memberikan nuansa keagamaan mata kuliah-mata kuliah umum dan kemudian menigntegrasikannya ke dalam orde dan hirarki keilmuan Islam. Keempat, mengintegrasikan semua disiplin ilmu dalam satu kerangka kurikulum, yang tentu saja melalui perombakan kurikulum. ${ }^{14}$

\footnotetext{
${ }^{10}$ Abdurrahman Mas'ud, Menggagas Format Pendidikan Nondikotomik: Humanisme Religius Sebagai Paradigma Pendidikan Islam (Cet. IV; Yogyakarta: Gama Media, 2007), h. 144-153.

${ }^{11}$ Abdurahman Mas'ud, et.al., Paradigma Pendidikan Islam (Cet. I; Yogyakarta: Pustaka Pelajar, 2001), h. 103.

${ }^{12}$ M. Zainuddin, Paradigma Pendidikan Terpadu: Menyiapkan Generasi Ulul Alba $>b$ (Malang: UIN Malang Press, 2008), h. 82.

${ }^{13}$ Abuddin Nata, op.cit., h. 154.

${ }^{14}$ Kuntowidjoyo, Paradigma Islam: Interpretasi untuk Aksi (Cet. I ; Bandung: Mizan, 2008), h. 284.
} 
Abdurrahman Wahid, sebagaimana di tulis Dedy Djamaluddin Malik mengusulkan kerangka pemikiran dalam mengembangkan kembali tradisi keilmuan dalam Islam, yaitu: pertama, orientasi ilmu pengetahuan haruslah ditujukan kepada pemenuhan hakiki umat manusia; kedua, wawasan ilmiah tradisi keilmuan yang dikembangkan haruslah memiliki liputan universal; ketiga, harus dilakukan pembedaan yang tajam antara kepentingan Islam sebagai sebuah agama dan kepentingan institusional lembaga-lembaga yang berdiri atas nama agama. ${ }^{15}$

Di samping itu, Amin Abdullah memberikan solusi dalam menghilangkan dikotomi dalam sistem pendidikan Islam di Indonesia dalam bentuk Horizon jaring laba-laba keilmuan TeoantroposentrikIntegralistik dalam UIN. Hubungan teoantroposentrik-integralistik horizon keilmuan integralistik sekaligus terampil dalam perikehidupan sektor tradisional maupun modern karena dikuasai oleh salah satu ilmu dasar dan keterampilan. Umat Islam mesti terampil menangani dan menganalisis isuisu yang menyentuh problem kemanusiaan dan keagamaan di era modern dengan berbagai pendekatan ilmu seperti natural science, social science, dan humanities kontemporer. ${ }^{16}$

\section{Epilog}

Dari pemaparan nilai-nilai Islam di atas, terlihat betapa pentingnya nilai-nilai universal itu diintegasikan ke dalam ilmu pengetahuan umum, karena nilai tersebut sangat menjaga kemaslahatan manusia, alam dan

${ }^{15}$ Dedy Djamaluddin Malik dan Idi Subandy Ibrahim, Zaman Baru Islam: Pemikiran dan Aksi Politik Abdurrahman Wahid, M. Amin Rais, Nusrcholis Madjid, dan Jalaluddin Rakhmat (Cet. I; Bandung: Zaman Wacana Ilmu, 1998), h. 187.

${ }^{16}$ Amin Abdullah, Islamic Studies di Perguruan Tinggi: Pendekatan IntegratifInterkonektif (Cet. I; Yogyakarta: Pustaka Pelajar, 2006), h.106. 
lingkungan, atau dengan kata lain nilai-nilai tersebut akan menjadi obor bagi manusia dalam mengembang tugas sebagai khalifah dan menuntun manusia dalam menjalankan tujuan hidupnya sebagai 'abdi. Oleh karena itu para ilmuwan yang beragama Islam dituntut peran tanggungjawabnya dalam mengintegrasikan nilai-nilai tersebut ke dalam bidang ilmu pengetahuan yang ditekuni masing-masing. Sehingga tidak ada lagi anggapan bahwa para ulama-lah yang notabenenya yang mempunyai tugas untuk itu, karena mereka diberi tugas mengelola bidang agama. Di samping itu sangat diharapkan bagi ilmuwan muslim agar selalu bersifat sosial dan spiritual, dan menolak netralitas ilmu pengetahuan.

Di dalam batasan nilai-nilai itulah umat Islam bebas mengekspresikan kemauan-kemuannya dalam memenuhi kebutuhan hidupnya sejauh mekanisme yang telah digariskan oleh nilai-nilai tersebut. Dengan mekanisme inilah, peradaban Islam senangtiasa berubah dan berkembang tetapi tetap mempertahankan karakteristiknya yang unik dan abadi. Dengan demikian, upaya mengintegasikan nilai-nilai Islam ke dalam ilmu pengetahuan, merupakan salah satu upaya dari islamisasi pengetahuan yang dipahami sebagai upaya membangun kembali semangat umat Islam dalam berilmu pengetahuan, mengembangkannya melalui kebebasan penalaran intelektual dan kajian rasional-empirik atau semangat pengembangan pengembangan ilmiah yang merupakan dari sikap istiqamah terhadap ajaran dan nilai-nilai Islam yang terkandung di dalam Al-Qur'an dan hadis. 


\section{Daftar Referensi}

Abdurahman Mas'ud, et.al., Paradigma Pendidikan Islam Cet. I; Yogyakarta: Pustaka Pelajar, 2001

Abdurrahman Mas'ud, Menggagas Format Pendidikan Nondikotomik: Humanisme Religius Sebagai Paradigma Pendidikan Islam Cet. IV; Yogyakarta: Gama Media, 2007

Abubaker A. Bagader, Islamisasi Ilmu Pengetahuan" dalam Islam dan Perspektif Sosisologik Cet. I; Surabaya: Amarpress, 1991

Ahmad M. Saefuddin, et al, Desekularisasi pemikiran: Landasan Islamsasi Cet. IV; Bandung: Mizan Anggota IKAPI, 1998

Amin Abdullah, Islamic Studies di Perguruan Tinggi: Pendekatan IntegratifInterkonektif (Cet. I; Yogyakarta: Pustaka Pelajar, 2006), h.106

Azyumardi Azra, Paradigma Baru Pendidikan Nasional Cet. I; Jakarta: PT. Kompas Media Nusantara, 2002

Dedy Djamaluddin Malik dan Idi Subandy Ibrahim, Zaman Baru Islam: Pemikiran dan Aksi Politik Abdurrahman Wahid, M. Amin Rais, Nusrcholis Madjid, dan Jalaluddin Rakhmat Cet. I; Bandung: Zaman Wacana Ilmu, 1998

Kuntowidjoyo, Paradigma Islam: Interpretasi untuk Aksi Cet. I ; Bandung: Mizan, 2008

M. Zainuddin, Paradigma Pendidikan Terpadu: Menyiapkan Generasi Ulul Albab Malang: UIN Malang Press, 2008

Maurice Bucaille, The Quran and Science, disunting oleh Khozin Afandi, Pengetahuan Modern dalam al-Qur'an Cet. I; Surabaya: Al-Ikhlas, 1995

R.H.A. Sahirul Alim, Menguak Keterpaduan Ilmu pengetahuan, Teknologi dan Islam Cet. I; Yogyakarta: Titian Ilahi, 1998

Syed Sajjad Husain dan Syed Ali As\}raf, Crisis Muslim Eduction, terj. Rahmani Astuti, Menyongsong Keruntuhan Pendidikan Islam Cet. V; Bandung: Gema Risalah Press, 1994

Ziauddin Sardar, Jihad Intelektual; Merumuskan Parameter-parameter Ilmu pengetahuan Islam, diterjemahkan oleh AE Priyono Cet. I; Surabaya: Risalah Gusti, 1998 
The Future of Muslim Civilization, terj. Rahmani Astuti, Rekayasa Masa Depan Peradaban Muslim Cet. III; Bandung: Mizan, 1991 